\title{
Editorial
}

\section{To Mask or Not to Mask? That is the question}

On May 13, 2021, the Center for Disease Control and Prevention (CDC) publicly announced that masks and social distancing were no longer necessary in public places for those that were vaccinated $[1,2]$. At the same time, the United States (U.S.) COVID-19 rate was 35,442 new cases per day and $59 \%$ of adults had been vaccinated [3]. Concurrently, the World Health Organization (WHO) continued to recommend wearing a mask indoors for all individuals vaccinated or not, even if the CDC did not [4, 5]. On July 27, 2021, almost 12 weeks later, the CDC revised its guidance indicating that "fully vaccinated or not, people who live where coronavirus transmission is classified as substantial or high should wear masks when they are indoors in public places. The agency also called for universal mask-wearing in K12 schools, where masks should be worn by teachers, other staff members, students and visitors. The recommendation applies to everyone over the age of 2 [6]." When the CDC's revised its guidelines on July 27, 2021, the U.S. COVID-19 rate was 42,226 new cases per day and the daily deaths were 239 which were reported as $45 \%$ higher than the low of 164 on July 10, 2021 [7]. During the 12 weeks of relaxation of masks in public places, there were 27,691 deaths and 1.8 million new COVID-19 cases in the U.S. [3, 7]. What would those numbers be if we had continued with wearing masks indoors, vaccinated or not?

On August 10, 2021, the Johns Hopkins COVID19 Situation Report noted that Florida was number one nationally in terms of both total weekly incidence and mortality, representing $22 \%$ and $25 \%$ of the national total respectively. Furthermore, it acknowledged that the governor had threatened to withhold pay for school administrators who instituted mask mandates during the state's most severe surge to date, which included a record high for pediatric hospital admissions [8]. On August 17, 2021, the first federal lawsuit was filed against the Texas governor for prohibiting mask mandates as it puts "students with disabilities at significant risk, is discriminatory, and violates the federal Americans with Disabilities Act and Section 504 of the federal Rehabilitation Act [9]."

With our guest editors Matthew Mc Laughlin and Christian Vercler, we published the 2020 JPRM special COVID-19 13.3 issue. To recap from my editorial, initially, we were told the virus was transmitted by touching various surfaces, the length of time it lasted on paper, versus plastic, versus carboard, and that masks weren't necessary. Next, scientific evidence revealed that masks were important to wear to stop the spread of the virus [10].

Typically, articles in JPRM do not implicate life or death. With the vaccines not being $100 \%$ effective and vaccinated and unvaccinated individuals having similar loads of COVID-19 virus, the approach to this global pandemic must include mask wearing [11]. Florida has demonstrated a frightening outcome from the failure to wear masks in public places. As adults tend to criticize youth for risk taking behavior, what risks are we taking by going mask-less? Everyone likely wants to put the pandemic behind them. However, it doesn't make sense to have reduced masks restrictions when the length of protection and the effectiveness of the vaccine against COVID-19 variants is unknown. We are now talking about a booster shot and some researchers are upset regarding the same. "Surgeon General Vivek Murthy insisted the booster dose program would only go ahead if sanctioned by the FDA and the ACIP, as the CDC advisory committee is known. But the fact that there is a fixed date for the start of the booster program led some to wonder if the outcome had already been decided." 
Also, there is concern that vaccinating Americans with a third dose is at the expense of providing vaccines to the rest of the world [12].

In the U.S. the CDC liberalized mask recommendations when our COVID-19 rates were 35,442 a day. On August 17, 2021, New Zealand went into lockdown with their first positive COVID-19 case in 6 months [13]. Did the CDC base easing mask restrictions on a few weeks' worth of data only to change their minds, 1.8 million cases and 27,691 deaths later? What if manuscripts sent to JPRM were based on author's recommendations, just weeks' worth of data and without blinded (de-identified) expert and statistical review? Each manuscript submitted to JPRM goes through a laborious review process electronically tracked by elaborate software. I am confident that if the manuscripts in JPRM were based on weeks of data that we would not be acting in the best interest of our readers who look to JPRM for guidance in the complex management of the patients that we serve globally.

According to Amnesty International, at least 17,000 health workers have died from COVID-19 over the last year [14]. That is approximately 47 health care worker deaths a day. Until we have zero COVID-19 cases, we must continue to be careful, and protect our families, friends, and those that we rely on to provide medical care for all of us. Seriously, if we continue to fight about masking or not masking, the Delta variant and all the variants to follow will win. This global pandemic calls for us all to be heroes, set the example as adults, keep the economy going, get in the groove, put our masks on and save lives. The life you save may be your own or that of someone you love.

\section{Sincerely, Elaine L. Pico, MD, FAAP, FAAPM \& R Editor-in-Chief Journal of Pediatric and Rehabilitation Medicine}

Please donate to our editorial office and programs through Foundation for Physical Medicine and Rehabilitation: http://foundationforpmr.org/supportthe-journal-of-pediatric-rehabilitation-medicine/

\section{References}

[1] Cohen E., Bonifield J. People vaccinated against Covid19 can go without masks indoors and outdoors, CDC says. Cable News Network (CNN) [Internet]. 2021 May 13 [cited
2021 Aug 22]. Available from: https://www.cnn.com/2021/ 05/13/health/cdc-mask-guidance-vaccinated/index.html.

[2] Wamsley L. Fully Vaccinated People can Stop Wearing Masks Indoors and Outdoors, CDC says. National Public Radio (NPR) [Internet]. 2021 May 13 [cited 2021 Aug 22]. Available from: https://www.npr.org/2021/05/13/9965 82891/fully-vaccinated-people-can-stop-wearing-masksindoors-and-outdoors-cdc-says.

[3] Johns Hopkins Center for Health Security. COVID-19 Situation Report May 14, 2021 [Internet]. 2021 May 14 [cited 2021 Aug 22]. Available from: https://www.center forhealthsecurity.org/resources/COVID-19/COVID-19SituationReports.html.

[4] Mereli A. The WHO still wants you to wear a mask, even if the CDC doesn't. Quartz [Internet]. 2021 Jun 28 [cited 2021 Aug 22]. Available from: https://qz.com/2025962/whoguidance-is-to-wear-masks-against-delta-variant/

[5] World Health Organization. Coronavirus disease (COVID19) advice for the public: When and how to use masks [Internet]. 2020 Dec 1 [cited 2021 Aug 22]. Available from: https://www.who.int/emergencies/diseases/novel-coronavi rus-2019/advice-for-public/when-and-how-to-use-masks.

[6] Goldstein A. What you need to know about the CDC's new mask guidance. The Washington Post [Internet]. 2021 Jul 28 [cited 2021 Aug 22]. Available from: https://www. washingtonpost.com/health/2021/07/27/new-cdc-maskguidelines/.

[7] Johns Hopkins Center for Health Security. COVID-19 Situation Report July 27, 2021 [Internet]. 2021Jul 27 [cited 2021 Aug 22]. Available from: https://www.center forhealthsecurity.org/resources/COVID-19/COVID-19SituationReports.html.

[8] Johns Hopkins Center for Health Security. COVID-19 Situation Report August 10, 2021 [Internet]. 2021 Aug 10 [cited 2021 Aug 22]. Available from: https://www. centerforhealthsecurity.org/resources/COVID-19/COVID19-SituationReports.html.

[9] Disability Rights Texas. First Federal Lawsuit Filed Against Texas Governor Says Mask Mandate Ban Violates ADA, Section 504 [Internet]. 2021 Aug 17 [cited 2021 Aug 22]. Available from: https://www.disabilityrightstx. org/en/press_release/federal-lawsuit-texas-mask-mandateban/.

[10] Pico E. COVID-19's Impact on the Practice of Pediatric Rehabilitation Medicine. J Ped Rehab Med. 2020;13(3):225-27. https://doi.org/10.3233/PRM-200027.

[11] Subbaraman N. How do vaccinated people spread Delta? What the science says. Nature [Internet]. 2021 Aug 12 [cited 2021 Aug 22]. Available from: https://www.nature. com/articles/d41586-021-02187-1.

[12] Branswell H. U.S. officials' decision on Covid-19 booster shots baffles some scientists. Stat News [Internet]. 2021 Aug 18 [cited 2021 Aug 22]. Available from: https://www. statnews.com/2021/08/18/u-s-decision-on-covid-19booster-shots-baffles-and-upsets-some-scientists/.

[13] British Broadcast Corporation (BBC). New Zealand enters nationwide lockdown over one Covid case [Internet]. 2021 Aug 17 [cited 2021 Aug 22]. Available from: https://www. bbc.com/news/world-asia-58241619.

[14] Amnesty International. COVID-19: Health worker death toll rises to at least 17,000 as organization call for rapid vaccine rollout [Internet]. 2021 Mar 5 [cited 2021 Aug 22]. Available from: https://www.amnesty.org/en/latest/news/ 2021/03/covid19-health-worker-death-toll-rises-to-at-least -17000-as-organizations-call-for-rapid-vaccine-rollout/. 